\title{
Barriers to Clinical Supervision Practices in Botswana Schools
}

\author{
Bernard Moswela $^{1}$, Luke Moloko Mphale ${ }^{1}$ \\ ${ }^{1}$ University of Botswana, Botswana \\ Correspondence: Bernard Moswela, University of Botswana, Botswana
}

Received: June 10, 2015 Accepted: June 26, 2015 Online Published: August 27, 2015

doi:10.11114/jets.v3i6.1054 URL: http://dx.doi.org/10.11114/jets.v3i6.1054

\begin{abstract}
This study was conducted to investigate possible barriers to the effective implementation of clinical supervision in Botswana primary schools, junior and senior secondary schools. Since the study sought views, experiences and observations of respondents, it adopted a qualitative approach to data collection. Teacher practitioners on study leave at the University of Botswana formed the subjects of the study. Data were analysed by being categorised into themes. The findings of the study revealed three major themes deemed to be barriers to clinical supervision practices. These are; large class sizes; the implementation of the Performance Management System in schools; and senior teachers who are designated as supervisors to junior teachers simply by virtue of their official position and not because they are experts in the areas they supervise. Recommendations were made on how these barriers could be addressed in order to facilitate clinical supervision activities in schools.
\end{abstract}

Keywords: performance management system, class size, barrier, clinical supervision

\section{Introduction}

As the downward spiral of students' academic performance in Botswana schools continues, clinical supervision promises to be the panacea to this public concern. Properly implemented, it has the potential to improve classroom performances because it promotes dialogue between teachers and their supervisors; thus fostering the professional growth of teachers (Colantonio, 2005). Clinical supervision needs to be a designated and binding role to those in senior posts in schools. Today the supervision of teachers remains an option and not mandatory to schools (Moswela, 2010). In this paper, the concept of clinical supervision is unpacked against the more familiar term 'instructional supervision' so that the thin distinction between the two is understood. The paper proceeds to discuss elements from the findings that impede the effective implementation of clinical supervision in schools and make recommendations on how these impediments can be addressed.

\section{Background}

The performance of students in the public examinations at all the levels of primary, junior and senior secondary schools in Botswana has seen a continued decline over the years (Mosarwe, 2015). The United Nations Education Scientific and Cultural Organization's (UNESCO, 2013) review of Botswana's Basic Education system has revealed that students perform below par compared to international students of the same age group and below that of high and middle income countries with whom Botswana must compete. The decline is in part attributed to the outdated method and practice used by teachers. This, the Report indicates, is compounded by lack of training related to the new curriculum resulting in teachers often not being in a good position to implement the curriculum properly. This observation has implications for the quality of the teacher and for the need to develop the teacher for quality teaching and students' learning. In order to identify the specific training needs of the teacher, classroom clinical supervision becomes imperative. The role of clinical instructional supervision is to offer guidance to teachers so that they improve instructional delivery to students (Mohammed, 2001). "The process of supervising a teacher . . . involves direct assistance to improve the strategies of classroom practice through observation and evaluation of teacher performance" (Mohammed, 2001, p. 326). Pansiri (2008, p.487) adds that, "Supervision aims at improving the teachers' quality of classroom work with the ultimate goal of raising learners' achievement as well as improving their attitudes and behaviour towards school work and personal life".

However, in Botswana schools, the implementation of this performance improvement strategy is constrained by among other things; big class sizes, lack of personnel who have learned instructional supervision formally; and the introduction 
of the Performance Management System (PMS) into the Public Service including in schools which is alleged to have diverted supervisors' and supervisees' attention from the teaching objectives. In order to improve the performance of all students, supervisors recommend a strength-based teaching approach that takes into account each individual student's strength and weakness (Kaplan, 1999). This pedagogical framework positions individual learners at the heart of the instructional process and does not treat them as passive recipients of information (Mahendra, Bayles, Kim, \& Tomoeda, 2005). It is commonly known as learner-centred teaching that takes into account, the diverse learning abilities of students. In this approach, students are not treated as though everyone were just alike. Some students prefer to work on their own and others are creative and artistic and like plenty of interaction. Teacher/student ratios in Botswana schools do not facilitate such diversity in teaching methods which allow self-paced learning. The Botswana Education and Training Sector Strategic Plan (2015-2020) in its report observed that overcrowding in classrooms and high pupil-teacher ratio, poses a major challenge that impacts on students' performance outcomes. According to Botswana Statistics (2004), in Moalosi (2012), although at primary and secondary schools, teacher ratio should be 1:28 and 1:40 respectively most of the classrooms designed to accommodate 35 students far exceed these numbers.

Supervisors who are designated supervisory functions have not been trained in this role. They were promoted through the ranks from the classroom as good teachers without any formal training or induction on matters pertaining to their roles as instructional leaders (Ratsatsi, 2005). By being good at classroom teaching, does not necessarily mean that one possessed the requisite skills needed to be a good supervisor; the two are not orthogonal. The new role of being an instructional leader requires a new body of knowledge and different skills. Monyatsi et al. (2008, p.2) corroborate Ratsatsi's argument thus: "Many school heads and other members of the School Management Team (SMT) were thrown into the deep end with none or very minimal management skills and experience". Adding to this, the multiple roles of heads limit the time they can devote to instructional supervision. They spent a great deal of time dealing with mundane managerial issues as opposed to instructional issues, confined to their offices with little clue of classroom happenings. This is because there is no formal structured training for heads in instructional supervision (Ministry of Education, 2006). Grauwe (2001) noted that instructional supervision, a strategy that clinical supervision draws from, has not been successful in Botswana and in other African countries because of its ambiguity in its function A study by Moswela (2010) on instructional supervision in secondary schools in Botswana concluded that instructional supervision still follows old practices akin to inspection, where the process lacked collegiality and supervisee growth. The study revealed the supervision to be "a self-serving activity with the motive to punish" (Moswela, 2010, p. 84), and that if it were practised according to intended purposes, it is a good thing that can improve instruction and students' performance.

The introduction of the Performance Management System (PMS) in schools, which required school heads to implement and supervise it, has not helped improved curriculum supervision in schools (Isaiah \& Isaiah, 2014). PMS was introduced in Botswana in 1996 as a change and quality management process of identifying, measuring and developing performance at the work place by linking each individual's performance and objectives to the organization's overall goals (Republic of Botswana, 2002; Anguish, 2011). The innovation lacked clarity of purpose to school supervisors, but regardless, they are obligated to supervise its implementation by virtue of their administrative positions. Buttressing this concern, Bulawa (2014) points out that there is too much emphasis on PMS whose objectives are isolated from classroom teaching and from clinical supervision. It is not an instructional curriculum programme with clear aims, objectives and methodological approaches. This confuses teachers as exactly what their core business is. Teachers have not much embraced and owned PMS as integral in the teaching curriculum. They resist it and view it as something imposed and not having much bearing on the improvement of teaching and learning, he further decried. The PMS specific goals are to:

- Provide a planning and change management framework that is linked to the national development planning and budgeting process to ensure that the people of Botswana get maximum benefit out of the national resource use;

-Enhance the capacity of the public service delivery more efficiently and effectively, pitch itself at the desired level of socio-economic governance and be able to compete at the global level;

-Improve the capacity of the public servants to be more productive; and

- Focus the efforts of the Public Service on the facilitation of the achievement of the Vision 2016 (Botswana Government, 1996, p5-6).

\section{The Problem}

Research on education often makes recommendations that have implications for policy formulation or review or change. This study is no exception to this trend. Debate on the decline in school performances, has close to a decade, dominated other issues that are a concern to education. The issue of falling academic results which transcends society at large, needs a change or a new policy in the operation of schools relating to particularly classroom teaching. However, the 
problem researchers often make for improvement in a particular area of education, unless the research was sponsored by the ministry, is that the recommendations hardly reach policy makers who can influence change and in the rare event the research products are deposited at the ministry, they gather dust unread. The researchers will take advantage of the occasional conferences organized by the Ministry of Education and Skills Development, to disseminate the results to the policy makers through conference resolution sessions. Policy formulation or review or change should inform good clinical supervision practice. The continual drop in Botswana schools performance has prompted us (the researches) to conduct this study; with the strong contention that clinical supervision, a somewhat neglected classroom improvement strategy, is an area which if given attention, can improve classroom teaching and learning outcomes significantly.

\section{Aim of the paper}

This paper is aimed at obtaining teacher practitioners' insights into how clinical supervision is being practised in Botswana schools and their views on barriers that affect such practice. Recommendations on how the barriers can be addressed are made.

\section{Research Questions}

a. What is the nature of clinical supervision practice in schools?

b. How do class sizes affect clinical supervision in schools?

c. What are the objectives of the Performance Management System (PMS) in schools?

\section{Clinical Supervision: A Conceptualization}

One of the most effective ways to bring about teaching improvement and professional growth and development of teachers is through well-organized in-service programmes that are likely to develop teachers' skills in teaching and in the use of modern visual aids. One such programme is instructional supervision which needs to be conducted by senior staff in the school who are specialists in the area of supervision and not by consultants who are far removed from real classroom happenings. The specialists senior staff members are referred here as clinical supervisors.

The term supervision connotes interaction between two or more people, one overlooking the work of the other in a seniority setting. In a school setup the interaction is of a social nature with the aim of coaching the junior member. The word 'clinical' on the other hand conveys an image of face-to-face relationship between supervisor and the supervisee (Pajak, 1993). Clinical supervision can be said to be a diagnostic observation "that invokes images of doctors and laboratory technicians analysing and diagnosing a patient's condition" (Oliva, 1993, p.475) with a view to improve the condition. The term was borrowed from the medical profession and used to describe a process of perfecting the specialized knowledge and skills of practitioners. In schools, the close supervision is intended to increase the teachers' work performance by receiving guidance from more knowledgeable and skilled mentor teachers, in less formal procedures or designated supervisor who has observed the teacher's performance in classroom teaching (Pajak, 1993). A razor blade or thin difference exists between clinical supervision and instructional supervision if one is to make a distinction between the two terms. The difference is explained by the term 'clinical' that suggests, as pointed out, a more diagnostic and close scrutiny of classroom teaching. Clinical supervision can be said to be instructional supervision that has been perfected; that is, a more structured and more analytical supervision that looks deeply into the teacher's practice and behaviour in the classroom conducted in a close and helping relationship. In context of this paper, a distinction also needs to be made between a clinical or instructional supervisor and a school head from the outset. A clinical or instructional supervisor, although it can be a school head, is not necessarily always the case. The context of this paper portrays a clinical supervisor as a member of the teaching staff other than the school head, who because of his/her experience, knowledge and skill in a particular subject, offers professional guidance to others in the area through the process of supervision. In schools, generally, the heads of department and other teachers in posts of responsibility are personnel who are tasked to lead clinical supervision activities.

The process of clinical supervision, for it to be effective, must be guided by objectives known and agreed upon by both the supervisor and his/her protégé, not as a formality for administrative purposes but for the teacher's ownership and developmental purposes. This sense is put thus; the teacher must believe that the goal of clinical supervision process is to foster formative growth within the environment (Drake \& Roe, 2003) and not grading performance (Colantonio, 2005). Involving teachers in their own 'thing' is participatory teaching and management of the teaching and learning activities (Smyth, 1994) that empowers teachers and raises their morale and commitment (Zapeda, 2002). Lovell and Wiles (1983, p.170) buttress the sense of clinical supervision as a two way transparent process thus: “. . . process in which professionals assume that they can give or receive help, support or service from others" and that "teaching can be improved by a formal collaboration between teacher and supervisor". Sullivan and Glanz (2000, p.19) describe clinical supervision "as a process of which the supervisor and the supervisee are responsible" (Sergiovanni \& Starratt, 2002). Subordinates tend to respond better to a positive, fair and democratic supervisor than to an impossible, autocratic leader 
(Westhuizen, 1999).

Major assumptions of clinical supervision are that; it focuses on the supervisee's strengths because he/she has a large reservoir of talent that can be developed. "It is a democratic, dialogic enterprise that offers teachers alternative approaches to improvement of instruction" (Pajak, 1993, p.22). Having goals is one step but having a strategy for reaching the goals is another. Sergiovanni (2006); Pfeither and Dunlap (1982); Glickman, Gordon and Ross-Gordon (2004); and Ndebele (2013) offer a model or structure or process for clinical supervision based on the participation of two people, a dialogue necessary for effective practice advocated by Sullivan and Glanz and Sergiovanni and Starratt above. The model developed by Goldhammer (1969) consists of the following phases. The model describes both the roles of the supervisor and the supervisee in the clinical supervisory dialogue. Typical of this model is its emphasis that the supervisor and the supervisee discuss and agree upon the areas of focus on the observation. The supervisor/supervisee relationship is suspended and a collegiality or an equal partnership approach adopted where views from both parties are accommodated but not necessarily agreed upon. The guiding principle is what works best for the intended purpose of clinical supervision, irrespective of source.

\subsection{The process of Clinical Supervision}

\subsubsection{Pre-observation Conference}

The teacher shows the supervisor his/her lesson plan and orally describes to the supervisor what and how he/she intends doing and what students are expected to do and learn from the lesson. Where there is need for clarity, the supervisor will ask for it and offer expert advice on any necessary adjustments which can improve the lesson delivery.

\subsubsection{Classroom Observation}

As the teacher delivers the lesson, the supervisor records occurrences related to the lesson for example, teacher and students' behaviour triggered by the lesson, for analysis at the end of the lesson

\subsubsection{Analysis and Interpretation}

The analysis is meant to make sense of the documentation made during the observation phase. Data could have shown the strength and/or weakness exhibited by the teacher. Following this, the way forward on how the conference will begin and end can be mapped.

\subsubsection{Conference Session}

The aim of this phase is to help the teacher to perform more effectively within the classroom. It involves giving each of the two critical friends a chance to make comments on how they viewed the lesson. As much as possible the supervisor should create an atmosphere of collegiality and avoid behaviour that can unsettle the teacher such as criticising him/her or making evaluative judgments about the teacher's ideas.

\subsubsection{Post-Conference}

This is the stage where the supervisor furnishes the teacher with feedback on the lesson observation. The feedback should be elicited directly from discussion of the recorded data so that the teacher implements for improvement what he/she has owned during the conference session. Clinical supervision leadership only becomes important and valuable if it is performed in a conversational way between the supervisor and the teacher.

\section{Methodology}

\subsection{Research Design and Method}

Before a design was decided upon for this study, the type of research was first determined as to whether it was descriptive, correlational or experimental. The study asked the main question 'what is the nature of instructional supervision in schools'? This question seeks answers in a descriptive form. The design which is a plan of the study then followed. As designs are associated mainly with qualitative, quantitative, or mixed methods, this particular study used the qualitative method which describes phenomena (http://www.nyu.edu/classes/bkg/methods/00582.

\subsection{Population}

Ary, Jacobs and Sorensen (2010) define population as the larger group of all members of any well-defined class of people or objects about which a generalized statement can be made. In order to pursue this study, specific institutions that are populated by people were identified as schools. The population of this study was therefore teachers. The smaller group of the population that is chosen to participate in a study is called population sample (Anderson, Herr, \& Nihlen, 1994). From the larger population, teachers on study leave from both primary and secondary schools were chosen as respondents. Teacher in-service training targets teachers who have served a minimum number of years. The study participants were undergraduate students at the University of Botswana who are qualified teachers, and have been temporarily released from their teaching duties at schools to pursue different education programmes offered at the 
university. These teachers would therefore be very familiar with school practices generally and, in particular, with how instructional supervision activities in schools are conducted. The in-service training is a four year duration degree programme that enrols all ranks from assistant teacher to school head.

\subsection{Sampling Procedure}

The population sample was initially purposive because it targeted people with experience and knowledge in the area of investigation and who are likely to provide informed and rich data on the subject (Bogdan \& Biklen, 2003). Three classes were randomly selected to participate and because most undergraduate class sizes exceed fifty, lecturers who agreed to administer the questionnaire randomly selected twenty students from each of the three classes. The initial target was 60 participants. This sample size is sufficient enough for a qualitative study (Wiersma \& Jurs, 2009). The participants were asked the geographical regions at which they were based before they enrolled at the university. The indication was that the sample was fairly well spread among all geographical regions of the country. Stratified sampling was used to select the sample by first identifying the different ranks/groups (seniority) and applied random selection on each rank/group to give all groups the same probability of selection and to increase the validity of the study outcomes (Brink, Walt \& Rensburg, 2014; Wellman, Kruger \& Mitchell, 2012).

\subsection{Data Collection}

The study was not concerned with cause-and effect relationships between variables and constructs but sought the expressed views, insights, observations and experiences of the participants. A semi-structured questionnaire where people would express their views at greater length (Ary, et al., 2010) was found most suitable to illicit such information. The cooperating lecturers were asked to solicit consent from the students on behalf of the investigators to participate.

\subsection{Data analysis}

The choice of method used to collect data dictated that the data be analysed by first carefully going through it looking for categories that would be broken into themes for discussion. As the data was presented in a narration of written words indicating observable behaviour, they were analysed descriptively (Anderson, et al., 1994). Factual data involving the number of years the participant has been teaching; the region where the participant last worked; average class size; were analysed by a simple count without having to resort to statistical packages because of the small number of participants involved.

\subsection{Instrument piloting}

The questionnaire was piloted to a similar group of students in the investigator's class. This group was not among the three classes that did the final study. The purpose of the pilot was to check on clarity of instructions and question items and to later remove any ambiguous items that may not yield useful data.

\subsection{Ethical issues}

These involved first seeking participants' consent to be involved in the study and assuring confidentiality. The investigators treated these as very important considerations in this study for two reasons namely; firstly, being cognizant of a possible assumption that because participants are students, therefore there is no need to seek their consent. Secondly, instructional supervision is sensitive in that participants may mention things which may not go well with their supervisors back at the schools.

\section{Findings}

This study sought the views of teachers on how clinical supervision in schools is being practised. It also investigated how teachers thought class size and the Performance Management System affected clinical supervision practices. The findings are reported on 45 teachers $(75 \%)$ who participated in the study out of the initial target of 60 . For whatever reasons, 15 prospective did not respond despite being reminded.

The findings on factual data are shown in Tables 1 to 3 below.

Table 1. Number of years teaching

\begin{tabular}{lllllll}
\hline Teaching experience & $10-14$ years & $15-19$ years & $20-24$ years & $25-29$ years & $30-34$ years & Total \\
\hline Number of respondents & 13 & 11 & 8 & 7 & 6 & 45 \\
\hline
\end{tabular}

Table 1 above shows that teaching is populated by teachers (71\%) with less than 25 years of teaching experience, while thirteen (29\%) are teachers with 25 years and above of teaching experience. Though the findings may not be generalized, they suggest that the teaching profession in Botswana is youthful. 
Table 2. Last regions of work

\begin{tabular}{|c|c|c|c|c|c|c|c|c|c|}
\hline $\mathrm{Re}$ & Central & Ghanzi & Southern & North East & Kweneng & Kgatleng & South East & West & Total \\
\hline er of respondents & 13 & 10 & 2 & 6 & 3 & 5 & 1 & 5 & 45 \\
\hline
\end{tabular}

Table 2 above reflects that out of ten regions in the country, eight were represented. The Central region had many respondents (29\%) followed by Ghanzi with ten $(22 \%)$ respondents, the region with very few (2\%) respondents was South East. A possible reason could be that the Central region as the biggest region would have the largest number of teachers sent for further education at the same time.

Table 3. Average class size in schools

\begin{tabular}{llllllllllllllllll}
\hline Class size & 30 & 31 & 32 & 33 & 34 & 35 & 36 & 37 & 38 & 39 & 40 & 41 & 42 & 43 & 44 & 45 & Total \\
\hline Number of respondents & 6 & 1 & 0 & 1 & 0 & 4 & 3 & 2 & 2 & 2 & 15 & 0 & 1 & 1 & 1 & 6 & 45 \\
\hline
\end{tabular}

Table 3 above shows class sizes ranging between 30 and 45 students. Twenty-four (53\%) respondents indicated their class size being 40-45 students and twenty-one (47\%) showing their class sizes being 30-39. This is an indication of how crowded Botswana class rooms are. None of the classrooms have less than 30 students, an official recommended maximum.

\subsection{Ideal Class size to a Teacher}

Table 4. Suggested teacher: student ratio

\begin{tabular}{llllll}
\hline Teacher/student ratio & $1: 20$ & $1: 25$ & $1: 30$ & $1: 35$ & Total \\
\hline Number of respondents & 16 & 22 & 6 & 1 & 45 \\
\hline
\end{tabular}

Table 4 above reflects the suggested teacher: student ratio of between 20 and 35. Twenty-two (49\%) respondents preferred 1:25 teacher: student ratio, followed by sixteen (36\%) who suggested a ratio of 1:20. Six (13\%) respondents suggested a ratio of 1:30, while one (2\%) preferred a teacher: student ratio of 1:35. The reasons given were for teachers to give individual students' full attention in order to improve their performance.

Table 5. Effectiveness of instructional supervision

\begin{tabular}{lllll}
\hline Questions & No & Yes & Somewhat & Total \\
\hline (b) Are the school supervisors formally trained? & 15 & 14 & 16 & 45 \\
(c) Do clinical supervision activities enhance classroom teaching? & 4 & 31 & 10 & 45 \\
(d) Do clinical supervision activities enhance students' learning and performance? & 3 & 34 & 8 & 45 \\
\hline
\end{tabular}

Table 5 above reflects the responses to the questions posed to judge the effectiveness of instructional supervision. The respondents were positive to the areas mentioned for development purposes. Thirty (67\%) affirmed that instructional supervisors have been trained, while fifteen $(33 \%)$ said the supervisors are not trained. As regard the instructional supervision activities ability to enhance classroom teaching, forty-one $(91 \%)$ believed they do, while four $(9 \%)$ felt that the activities do not enhance classroom teaching. On whether the instructional supervision activities enhance students' learning and performance, forty-two (93\%) respondents affirmed that the activities enhance students' learning and performance. Typical comments in favour of clinical supervision were that it:

- Boosts the morale of teachers;

- Promotes teacher effectiveness;

- Enhances and support teacher professional growth;

- Improves supervisor and supervisee's relationships;

- Promotes reflective teaching and

- Re-skills the teacher.

Regarding the objectives of Performance Management System (PMS), the respondents outlined teachers reward, improve teachers' performance, improve productivity, efficiency and effectiveness in the education system, and guide teachers in achieving the set objectives and goals as some of the objectives. The informants (83\%) believed that the objectives are related to classroom teaching in the sense that they can improve the quality of teaching and learning process if properly implemented. However, $17 \%$ hold a different view as exemplified in comments such as:

"They are relevant but in a limit way".

"PMS is not applicable to teaching. Teaching deals with imparting knowledge and assisting individual students. But large classes limit against differentiated teaching to address diverse students' ability".

"PMS objectives are not relevant to teaching because lazy teachers benefit from the efforts of others in the team. I feel it is not the duty of teachers to monitor colleagues. They monitor students instead. If one pulls down the team, the hard workers are affected".

In-as-much as they may be relevant, they consume the teacher's time to teach students. There is too much emphasis on record keeping and are too result-oriented". 
On matters relating to teachers' assessment, forty-three (96\%) believed that the method used to assess teachers on PMS is relevant to the objectives of teaching, as some teachers are rewarded (monetary and progression). They claim this boost staff morale. Only two (4\%) felt the method is irrelevant because PMS is result-oriented. One condemned the assessment as unfair and discouraging hard work: "What's the point of hard work when you can't be rewarded individually. My class passed well but other classes of the same level did not do well and I was not rewarded because on average the students as a group (assessed against other schools) did not do well that year.

Suggestions were made as to how clinical supervision can be improved in schools. Respondents generally suggested regular workshops on clinical supervision for the SMTs and teachers. They further suggested that supervisors need to supervise subjects they have specialized in and that induction sessions usually conducted on the newly appointed teachers should cover clinical supervision. One commented that since clinical supervision is meant to assist the teacher to improve teaching and students' learning, teachers should teach more manageable classes to assist students better. They felt that for effective supervision class sizes be reduced to 25 students (ratio of 1:25) and PMS objectives to be reviewed and aligned to the realities of teaching. Those who said PMS objectives were relevant to teaching suggested strict adherence to the objectives.

\section{Discussion}

The findings of this study suggest that teachers appreciate the important role clinical supervision plays as a tool that advances the learning activities of students (Glickman, et al. 2001). The informants also are aware that for clinical supervision to yield its purported outcomes it needs to be a structured process along the lines of Goldhammer's five phases of pre-observing; observing; analysing and interpreting; conferencing; and pre-conferencing. Like Sergiovanni (2006), Glickman et al. (2004), Ndebele (2013) and many others, respondents believed that this face-to-face approach of classroom observation and evaluation gives supervisees the opportunity to dialogue with their supervisors and receive useful feedback of their lessons on time. However, this can be achieved only if barriers that stand in the way of this effort are removed. These barriers include; inappropriate supervisors supervising subjects they do not have knowledge in, class sizes and the manner in which PMS is being implemented and assessed.

\subsection{Clinical Supervision Is A Specialist's Role}

The study has revealed that clinical supervision in Botswana schools is normally conducted by school heads, deputies, heads of houses, heads of department and senior teachers. According to Moswela (2010), Isaiah and Isaiah (2014) and Grauwe (2001), the process of instructional supervision has not been successful in Botswana schools because it did not take teachers aboard. Contrary to this view, this study shows that there has been an improvement in the way supervision is being conducted. In the majority of cases teachers are involved from the outset according to the majority respondents' view. This argues well with the perspectives by Drake and Roe's (2003), Sullivan and Glanz (2009), Sergiovanni and Starratt (2002) and many others that involving teachers in clinical supervision empowers and raises their morale and commitment (Zapeda, 2002). Going by the respondents' revelation, there has been a big and sudden improvement in the way supervision is being conducted in schools. However, the concern from $11 \%$ of the respondents is that it is wrongly assumed that anyone in a more senior position than the one being supervised can offer useful guidance in the supervision process. This concern emanates from the fact that in Botswana schools, a head of department or head of house for example, who overlooks a group of subjects some of which he/she has little or no knowledge in, is not the best suited to provide effective supervisory guidance. Because the nature of clinical supervision is akin to a doctor/patient relationship, the doctor (supervisor) needs training otherwise he/she will kill the patient (supervisee). Also, a more hardworking and committed supervisee may have more knowledge in the subject area than his/her supervisor. This anomaly is supervision allocation is a potential cause of misunderstanding and conflict between the supervisor and the supervisee particularly if the former forces his/her ideas or uses his/her administrative powers on the latter.

\subsection{Class Sizes:}

For teachers to improve students' performances, the diverse abilities and capabilities among students need to be taken cognizant of. Some scholars believe that proponents of differentiated teaching or learner-centred teaching and self-paced learning are the way to go towards improved students' academic success (Kaplan, 1999; Mahendra, et al., 2005). The success of this teaching strategy in Botswana is constrained by large classes which exceed 40 students. The reason for the big teacher: student ratios indicated in the findings is not so much of a shortage of trained teachers. Unlike in the past years where teachers were in short supply to the extent that teachers from foreign countries were recruited into the system, Botswana now has a surplus of teachers to the extent that newly qualified teachers from training institutions wait for a long time, sometimes years, before they can be absorbed into teaching. The big teacher: student ratios are a result of shortage of classroom accommodation (Moalosi, 2012). Class size is therefore one major determinant of the success of clinical supervision, because, practically, teachers are unable to effectively implement 
recommended improvement strategies emanating from clinical supervision.

\subsection{Performance Management System}

The objectives of the PMS emphasize the improvement of performance and service delivery at the work place. These are general objectives which can also apply to teaching. No wonder therefore that the big majority of respondents said that these objectives are relevant even to teaching, contrary to Bulawa (2014) who argued that the PMS objectives are isolated from classroom realities. They are too general to specify how teaching can be improved in order to improve students' academic performance. The PMS is evidence-based and its objectives are short term. They can be achieved within a specified period of time; a year. In PMS one can specifically say 'I have achieved and here is the material evidence'. Those of teaching are long term. If for example, a teacher's objective is to produce $10 \%$ first class passes in his/her class in the national examinations, it would take seven years (primary school) or three years (junior secondary) or two years (senior secondary) to achieve. Adding to this problem, since teachers exchange students from one year to another particularly at the primary school level, the achievement goals can be pointless. Seventeen percent (17\%) of the respondents criticize the PMS as paper driven, ensuring that records of activities are kept for end of year assessment. This, they argue, diverts attention from the core business of teaching. Teaching on its own has enough records to be kept such as class registers, scheme books, test, discipline case etc. The lonely voice of the minority who think that PMS is a stumbling block whose objectives do not have a bearing on effective clinical supervision and to students' academic improvement cannot therefore be ignored. Their views get support from a study by Bulawa (2014) on the impediments of the implementation of the PMS. The Performance Management System objectives, though may apply to the general Public Service in their form, they need to be customized to teaching to cater for the uniqueness of the profession.

\section{Conclusion}

Three important revelations that militate against the successful implementation of clinical supervision in Botswana schools have come out from this study:

Firstly, all the respondents are concerned that clinical supervision as a strategy meant to improve the teaching and learning processes will not effectively yield its intended purpose if teachers continue to teach large classes. The basis of this argument is that there is the likelihood that among the recommendations clinical supervisors will make, is one that advocates for teaching that takes cognizance of the individual's or small group's ability. Such a recommendation is very necessary particularly in Botswana junior secondary schools where students entering this level of learning have a wide range of abilities because they have been automatically promoted from the primary school irrespective of performance.

Secondly, there is the concern that clinical supervision is been led by people who are not necessarily qualified in the area of supervision. That, if those to lead clinical supervision do so only by virtue of their official position (seniority), clinical supervision will not be helpful in developing the teacher in his/her teaching activities.

Thirdly, regarding the PMS, there are mixed feelings (more skewed towards its efficacy) about its effectiveness to the teaching and learning activities. The majority did not view it as a barrier to the successful implementation of clinical supervision. Only a minority did, citing it as not benefiting teaching and learning because its objectives are not aligned to those of teaching.

\section{Recommendations}

Basing on the outcomes of the study, the following recommendations are made to the Ministry of Education and Skills Development:

- The Performance Management System is a work improvement tool that transcends all government departments. It needs to be customized in alignment with the teaching objectives so that it serves schools and their employees better and more appropriately.

- In order to make clinical supervision more effective in developing the teacher in his/her job and in improving the academic performance of students, those promoted to senior positions in schools should be inducted on clinical supervision activities and should only supervise in areas where they have expert knowledge.

-Qualified teachers who are not gainfully employed should be employed on permanent basis to reduce the wide teacher: student ratio presently limiting teachers to attend more to the individualized students' strengths and weaknesses.

\section{References}

Anderson, G. L., Herr, K., \& Nihlen, A. S. (1994). Studying your own School. An educator's guide to qualitative practitioner research. London: Corwin Press.

Anguish, H. (2011). Performance Management. Edinburgh.

Ary, D., Jacobs, L. C., \& Sorensen, C. (2010). Introduction to Research in Education (8 ${ }^{\text {th }}$ ed.). Belmont: Wadworth. 
Bogdan, R. C., \& Biklen, S. K. (2003). Qualitative Research for Education: An introduction to theory and methods ( $3^{\text {rd }}$ ed.). Boston: Allyn and Bacon.

Botswana Government (1996). Manual on Performance Management in the Public Service, Gaborone: Government Printer.

Brink, H., Walt, C., \& Rensburg, G. (2014). Fundamentals of Research Methodology for Healthcare Professionals ( $3^{\text {rd }}$ ed.). Cape Town: Juta and Company Ltd.

Bulawa, P. (2014). Impediments to Senior Management Team's (SMT) Role of Implementing the Performance Management System (PMS) in Senior Secondary Schools in Botswana. International Journal of Current Research and Academic Review, 2(3), 01-18.

Colantonio, J. (2005). On Target: Combined instructional supervision and staff development. Pennsylavania: University of Pennsylavania.

Drake, T. L., \& Roe, W. H. (2003). The Principalship (6 $6^{\text {th }}$ ed.). New Jersey: Prentice Hall.

Glickman, C. D., Gordon, S. P., \& Ross-Gordon, J. M. (2004). Supervision and Instructional Leadership: A developmental approach. Boston: Pearson.

Goldhammer, R. (1969). Clinical Supervision. New York: Holt, Reinhart and Winston

Grauwe, A. (2001). School Supervision in Four African Countries: Challenges and reforms. Internatioonal Institute for Educational Planning/UNESCO, 1(1). Retrieved from unesdoc.unesco.org/images/0012/001248/00124823e.pdf

Isaiah, A. M., \& Isaiah, M. N. (2014). Perceptions of Teachers on the Instructional Roles of School Heads in the Secondary School in Botswana. International Review of Social Sciences and Humanities, 7(1), 112-124.

Lovell, J. T., \& Wiles, K. (1983). Supervision for Better Schools. New Jersey: Prentice Hall.

Kaplan, K. C. (1999). Integrating Technology: Issues for traditional and constructivist pedagogies. Teacher Education, $15,14-18$.

Mahendra, N., Bayles, K. A., Kim, A, S., \& Tomoeda, C. (2005). Diversity and Learner-Centred Education, Retrieved from File://A:/htm.

Ministry of Education (2006). Unit 4: Providing Effective Instructional Leadership. Gaborone: Government Printer.

Moalosi, W. T. S. (2012). Teacher Eficacy: Is student engagement essential in Botswana Junior Secondary Schools? International Journal of Scientific Research in Education, 5(3), 2007-213.

Mohammed, T. (2001). Effects of Educational Supervision on Students' Academic Performance in Nadowli District in the Upper West Region of Ghana. The International Journal of Humanities and Social Studies, 2(6), 321-346.

Monyatsi, P. P., Tsayang, G., Bulawa, P. G., \& Mhozya, C. (2008). An Evaluation of the Impact of the PSMDP. Journal of Scientific Research in Education, 1(1), 1-12.

Mosarwe, Q. (2015, March 6). Another Generation Fail. The Botswana Gazette, p4.

Moswela, B. (2010). Instructional Supervision in Botswana Secondary Schools: An investigation. Educational Management Administration and Leadership, 38(1), 71-87. http://dx.doi.org/10.1177/1741143209351811

Ndebele, C. (2013). Prevalent Supervisory Styles in Primary Schools in Remote Rural District in Zimbabwe: Strategies for reconciling them with teacher preferred Supervisory .Stud Tribes Tribals, 11(1), 55-66.

Oliva, P. F. (1993). Supervision for To-day's Schools. New York: Longman.

Pansiri, N. O. (2008). Instructional Leadership for Quality Learning: An assessment of the impact of the Primary School Management Development Project in Botswana. Educational Management Administration and Leadership, 36(4), 471-494. http://dx.doi.org/10.1177/1741143208095789

Pajak, E. (1993). Approaches to Clinical Supervision: Alternatives for improving instruction. New York: Christopher-Gordon Publishers.

Pfeither, I. L., \& Dunlap, J. B. (1982). Supervision of Teacher: A guide to improving instruction. Encanto Phoenix: Oryx Press.

Ratsatsi, D. (2005). Instructional Supervision: Main obstacles to improving the functioning of schools in Botswana. Quality of Education in Botswana. wikieducator.org/usr:Motlhale.quality_of_education_in_Botswana.

Republic of Botswana (2002). The Performance Management Philosophy Document to the Botswana Public Service. Gaborone: Government Printer. 
Sergiovanni, T. J. (2006). The Principalship: A reflective perspective. Boston: Pearson.

Sergiovanni, T. J., \& Starratt, R. T. (2002). Supervision: A re-definition. Boston: McGraw-Hill.

Smyth, J. (1994). Critical Perspective on Educational Leadership. East Sussex: The Falmer Press.

Sullivan, S., \& Glanz, J. (2009). Supervision that Improves Teaching, Strategies and Techniques: California: Corwin Press.

The Botswana Education and Training Sector Strategic Plan (2015-2020). Gaborone: Government Printer

Wellman, C., Kruger, F., \& Mitchell, B. (2012). Research Methodology ( ${ }^{\text {rd }}$ ed.). Cape Town: Oxford University Press.

Westhuizen, P. C., Van der. (1999). Effective Educational Management. Cape Town: Kagiso Tertiary.

Wiersma, W., \& Jurs, S. G. (2009). Research Methods: An introduction ( $9^{\text {th }}$ ed.). Boston: Allyn and Bacon.

United Nations Education Scientific and Cultural Organization UNESCO (2013). New York: UNESCO.

Zapeda, S. J. (2003). Instructional Supervision: Applying tools and concepts. New York: Eye on Education.

This work is licensed under a Creative Commons Attribution 3.0 License. 